RU Синтаксис как средство достижения адекватности перевода рекламного дискурса с русского языка на английский

\author{
Цыремпилон А. О., Семенова Э. В., Марактаева С. В.
}

\begin{abstract}
Аннотация. Цель исследования - определить виды синтаксических структур, обеспечивающих достижение адекватности перевода англоязычного рекламного текста. Рассматриваются дискурсивные особенности англоязычного рекламного стиля и наиболее употребительные синтаксические конструкции. Научная новизна работы заключается в обосновании алгоритмизированного подхода к синтаксическому оформлению текста перевода на основе перечня наиболее частотных структур рекламного дискурса. В результате доказано, что необходим системный подход к синтаксическому оформлению текста перевода, основывающийся на анализе и обобщении дискурсивных характеристик аналогичных текстов переводящей лингвокультуры.
\end{abstract}

\title{
EN Syntactic Means Ensuring Adequate Translation of Advertising Discourse from Russian into English
}

\author{
Tsyrempilon A. O., Semenova E. V., Maraktaeva S. V.
}

\begin{abstract}
The paper aims to identify the syntactic structures ensuring adequacy of the English-language advertising text translation. The authors examine stylistic peculiarities of the English-language advertising discourse, analyse the most frequent syntactic constructions. Scientific originality of the study involves justifying relevance of the algorithmic approach to syntactic arrangement of a target text; such an approach is based on identifying syntactic characteristics of advertising discourse. The research findings are as follows: the authors justify the necessity of the systemic approach when choosing the syntactic structure of a target text; this approach is based on analysing syntactic characteristics of the Russian-language advertising discourse.
\end{abstract}

\section{Введение}

Актуальность темы исследования обусловлена растущей значимостью рекламы как социокультурного феномена и необходимостью разработки переводческих рекомендаций по достижению адекватности перевода этого вида дискурса. Переводчики зачастую уделяют большее внимание лексическо-грамматическому аспекту перевода, «механически» переводя синтаксические структуры, что ведет к утрате маркетинговой направленности. В этой связи переводо-ориентированные дискурсивные исследования, основанные на жанрово-узуальном анализе целевого языка перевода, не теряют своей актуальности.

Для достижения указанной цели ставятся следующие задачи: во-первых, рассмотреть общие характеристики рекламного стиля; во-вторых, провести сравнительно-сопоставительный анализ экспрессивного синтаксиса в рекламных текстах на русском и английском языках; в-третьих, предложить рекомендации для адекватного синтаксического оформления текстов рекламного дискурса при переводе.

Для решения поставленных задач применяются следующие методы исследования: сравнительно-сопоставительный, структурный, стилистический и прагматический.

Материалом исследования послужили рекламные тексты, размещенные в сети Интернет [2; 6-8; 10-13].

Теоретической базой исследования послужили работы исследователей в области рекламы (А. Н. Мудров, Б. Феннис, В. Штрёбе, Т. Н. Ефименко), лингвистики и переводоведения (Е. Н. Малюга, В. С. Слепович, Д. В. Псурцев).

Практическая значимость исследования заключается в разработке рекомендаций по переводу русскоязычных рекламных текстов на английский язык. Практический материал также может быть использован в качестве материала при проведении занятий по письменному переводу. 


\section{Определение рекламного дискурса}

На сегодняшний день в научной литературе по лингвистике насчитываются десятки дефиниций рекламного дискурса, что объясняется разнообразием подходов к его изучению. Применительно к нашей работе и вслед за Т. Н. Ефименко мы будем рассматривать рекламный дискурс как «коммуникативно-когнитивную речемыслительную деятельность, выполняющую прагматические, социокультурные, коммуникативные задачи и оказывающую влияние на формирование когнитивных процессов в условиях взаимодействия субъекта (говорящего) и целевой аудитории» [1, с. 39].

Рекламный дискурс, как известно, объединяет в себе две функции: информационную и воздействующую $[4$, с. 35 ; 9, р. 6]. Информационная функция направлена на предоставление определенного знания о товарах и услугах. Воздействующая функция ориентирована на формирование определенных стереотипов поведения, реконструирование и закрепление ценностных ориентиров в сознании личности; она превалирует в рекламном тексте, чьей задачей являются последовательное убеждение потенциальных клиентов в преимуществе рекламируемых товара/услуги, вызов интереса к приобретению данного продукта и так далее. Следовательно, средством убеждения выступает экспрессивная окраска, свойственная публицистическому и разговорному стилям. Говоря о соотношении информативной и воздействующей функций в рекламном тексте, психологи Боб М. Феннис (Bob M. Fennis) и Вольфганг Штрёбе (Wolfgang Stroebe) в своей книге “Тhe Psychology of Advertising” отмечают наличие сдвига в сторону возрастающей роли воздействующей функции [9, p. 10].

Отдельного внимания заслуживает и определение дискурсообразующих жанров рекламы как в русском, так и в английском языке. Стоит отметить, что попытки выделения рекламных жанров предпринимались неоднократно. Однако в научной литературе нет единой систематизированной классификации жанров рекламы в силу способности рекламы заимствовать особенности других жанров. Предположительно для всех рекламных жанров характерны интеграция и синкретизм, между ними нет четких границ.

\section{Экспрессивный синтаксис в рекламе: межъязыковое сопоставление}

В ходе сравнительно-сопоставительного анализа синтаксической системы в рекламных текстах на русском и английском языках мы выявили следующее.

1. В английских рекламных текстах наблюдается наиболее широкое распространение простых (односоставных и двусоставных) предложений, в то время как в русском языке сохраняется тенденция преобладания сложных типов предложений над простыми. Это связано с особенностями построения рекламы в обеих лингвокультурах: реклама на русском языке обычно содержит больше фактической информации, используется более официальный или нейтральный тон, в то время как реклама на английском тяготеет к синтаксической компрессии; длина предложения - важный критерий читабельности: чем длиннее предложение, тем ниже читабельность [3, с. 103]. Данный тезис подтверждается анализом материалов исследования, где средняя длина рекламных текстов на английском языке составила 31,12 слова; на русском языке - 45,9 слова.

2. В англоязычных рекламных текстах активно прослеживается императивность в виде побудительных предложений, направленных на прямолинейное обращение к адресату и мотивирование на приобретение товара или услуги. В русской лингвокультуре императивность имеет место быть, хотя применяется заметно реже: COKE LOVE from all over the country $\bullet$ Have you got your customized Coke bottle yet? Only 3 more days left! Hurry and head over to Hyde Park Corner Arpico today! \#ShareaCoke [7]. / Вся страна любит Coca-Cola $\bullet$ А ты нашел свою КокаКолу? Получи свою в Агрісо на Гайд-Парк-Корнер! Торопись: акция продлится еще 3 дня! \#ShareaСоке (здесь и далее перевод авторов статьи. - А. Ц., Э. С., С. М.). Стоит отметить, в последнее время рекламодатели все чаще стали включать эмодзи и хэштеги в качестве инструментов апеллирования к молодежи и языковой экономии.

3. В англоязычной рекламе выше плотность употребления синтаксических экспрессивных конструкций, таких как эллипсис, инверсия, парцелляция, параллельные конструкции, риторический вопрос.

Эллипсис является одним из известных средств компрессии в рекламе и отражает стремление воздействовать на адресата с помощью минимальной эксплицитной информации. Пропуск какого-либо элемента высказывания легко восстанавливается в контексте, например: Looking at accessories and shoes from Gucci Off The Grid now available in a new vivid blue color - featured in playful images created in collaboration with Highsnobiety. Designed for those mindful of their environmental impact, the Gucci Off The Grid collection uses recycled, organic, bio-based and sustainably sourced materials [10]. / Созданные в партнерстве с Highsnobiety аксессуары и обувь из коллекции Gиссі Off The Grid mеперь доступны в ярко-синей расцветке. Коллекция Guсci Off The Grid создана для тех, кто заботится об окружающей среде, и разработана в соответствии с идеей цииличного производства.

Инверсия используется как экспрессивно-стилистическое средство, выполняющее функцию воздействия с ее помощью достигается большая эмоциональность высказывания. Такая акцентуация за счет темарематических перестановок придает всему высказыванию определенную экспрессивность, не меняя главной мысли: Vegan? Vegetarian? Flexitarian? Whoever you are, whatever you're looking for, there's an Activia for you [8]. / Веган? Вегетарианец? Полувегетарианец? Кем бы Вы ни были, что бы Вы ни искали, для Вас всегда есть Асtіvіа.

Парцелляция - учащенное членение фраз, повышающее число значимых элементов в тексте посредством оформления их в отдельные предложения: Krave cereal. Tiny little pieces. Big chocolate taste [11]. / Хлопья Krave. Хрустящие подушечки. Вкус шоколада. 
Параллельные конструкции - одинаковое грамматическое построение следующих непосредственно друг за другом фраз или предложений. Повтор однородных слов в одном предложении несет эстетическую нагрузку (поддержание интереса), усиливает высказывание, сохраняет ритм: Own the room, own the sidewalk, own the lift. When you find your Ray-Ban style, you're always on air [13]./ Лови момент в офисе, на прогулке, в лифте. C очками от Ray-Ban ты всегда в центре внимания.

Риторический вопрос как средство экспрессии привлекает внимание, усиливает выразительность речи, позволяет разнообразить интонационный рисунок монологической речи. Характеризуется неформальностью, принадлежностью к разговорному стилю: Pss, did уоu know that you can find a lot of comfortable and trendy pyjamas in the online shop [12]? / Тсс, а ты знаешь, что модные и уютные пижамы можно найти в интернет-магазине?

\section{Синтаксическая адекватность перевода: рекомендации переводчику}

В качестве рекомендаций по переводу рекламных текстов с русского на английский язык мы, во-первых, предлагаем использовать вышеупомянутые синтаксические экспрессивные конструкции для усиления перлокутивного воздействия. Вдобавок, вслед за В. С. Слеповичем, мы считаем целесообразным указать следующие авторские советы как применимые к нашему случаю [5]:

1) одна и та же предметная ситуация в русском языке может быть по-разному выражена в английском языке;

2) тема в русском предложении помещается в начале предложения, а рема - в конце, в то время как в английском предложении они помещаются всегда в начале предложения, но отличаются артиклями (неопределенный или нулевой - перед ремой и определенный - перед темой);

3) членение высказываний при переводе, т.е. преобразование русского высказывания в два или более в английском тексте;

4) объединение высказываний (компрессия) при переводе с русского языка на английский;

5) использование средств экспрессивной разговорной речи и необходимых преобразований (стилистическая идиоматичность перевода).

Проиллюстрируем применение нашего подхода на практике (см. Табл. 1).

Таблица 1. Перевод рекламного текста с учетом синтаксического аспекта жанрового узуса целевого языка

\begin{tabular}{|l|l|}
\hline \multicolumn{1}{|c|}{ Исходный текст } & \multicolumn{1}{|c|}{ Перевод на английский язык } \\
\hline $\begin{array}{l}\text { Программа тура включает в себя посещение самых интерес- } \\
\text { ных и знаковых точек туристического притяжения в респуб- } \\
\text { лике - это столица Бурятии - город Улан-Удэ, озеро Бай- } \\
\begin{array}{l}\text { кал, Иволгинский дацан, Старообрядческое село Тарбага- } \\
\text { тай, священная долина Ацагат [6]. }\end{array}\end{array}$ & $\begin{array}{l}\text { tions of Russian Old-Believers in the village of Tarbagatay, and } \\
\text { hike about Atsagat valley! }\end{array}$ \\
\hline $\begin{array}{l}\text { В этно-маркете ZАМ представлены изделия мастеров Бу- } \\
\text { рятии - скульптуры, картины, украшения, книги, сувени- } \\
\text { ры и одежда [13]. }\end{array}$ & $\begin{array}{l}\text { Located in the heart of Ulan-Ude, ZAM offers a wide array } \\
\text { of goods - statues, paintings, jewelry, books, gifts, and clothes - } \\
\text { all made by local artists and artisans. }\end{array}$ \\
\hline
\end{tabular}

В качестве исходных текстов были взяты рекламные сообщения различных компаний г. Улан-Удэ, целевой аудиторией которых являются иностранные туристы. В первом примере в перевод были введены императивные параллельные конструкции, призывающие читателя посетить достопримечательности. Механический перенос синтаксической конструкции исходного текста чреват формальностью стиля и потерей маркетинговой составляющей. Второй пример отличается частным случаем инверсии в синтаксисе русского языка - сказуемое предшествует подлежащему. Будучи аналитическим языком, английский язык имеет фиксированный порядок слов, соответственно, в переводе необходимо произвести грамматическую трансформацию, а именно преобразовать обстоятельство места в английское подлежащее. Так, перевод претерпел изменения в синтаксической структуре: атрибутивное придаточное в начальной позиции, в главном предложении введен агент действия ZAM. Такое предложение с атрибутивным придаточным в препозиции является типичным для рекламного стиля английского языка, поскольку позволяет описать различные характеристики объекта и несет экспрессивную коннотацию, акцентируя указанные характеристики.

В результате апробирования нашего подхода перевод рекламного текста был осуществлен посредством введения экспрессивных синтаксических конструкций согласно контексту оригинала. В итоге текст перевода более эмоционально экспрессивен, сохраняет прагматический потенциал, соответствует нормам языка и жанровому узусу, а значит, достигается искомая степень переводческой адекватности.

\section{Заключение}

Нами сделаны следующие выводы: во-первых, воздействующая или апеллятивная функция рекламного стиля определяет выбор всех языковых и речевых средств, в том числе синтаксических, что актуализирует применение в текстах данного стиля конструкций экспрессивного синтаксиса и, напротив, указывает на неуместность применения структур формального стиля, таких как распространенные, сложносочиненные предложения. 
Во-вторых, выявлены основные различия в синтаксическом оформлении англоязычных и русскоязычных рекламных текстов: англоязычная реклама преимущественно использует краткие простые односоставные и двусоставные предложения, в то время как русскоязычная - более сложные синтаксические типы предложения. Англоязычной рекламе свойственна более высокая степень императивности. В англоязычной рекламе синтаксические экспрессивные конструкции (эллипсис, инверсия, парцелляция, параллельные конструкции, риторический вопрос) играют доминирующую роль, в отличие от русскоязычной. Примеры таких конструкций приведены выше.

В-третьих, можно рекомендовать переводчику стремиться к достижению синтаксической адекватности путем введения в текст перевода частотных экспрессивных конструкций, свойственных языку перевода; отметим, что такое вмешательство не должно рассматриваться как переводческая вольность.

Настоящее исследование имеет перспективы развития как в рамках перевода рекламного стиля (так, могут быть рассмотрены различные поджанры рекламы), так и в отношении иных функциональных стилей и жанров в силу актуальности идеи упорядочения и алгоритмизации применения переводческих приемов в век автоматизации межъязыковой коммуникации.

\section{Источники | References}

1. Ефименко Т. Н. Рекламный дискурс: функциональные и прагматические особенности англоязычного рекламного дискурса // Традиции и инновации в лингвистике и литературоведении: межкафедральный сборник научных статей. М.: Московский государственный областной университет, 2018. С. 37-47.

2. Легенды Бурятии [Электронный ресурс]. URL: http://www.visitburyatia.ru/tours/section-512/item-306448/ (дата обращения: 05.04.2021).

3. Малюга Е. Н. Синтаксические характеристики рекламного дискурса // Вестник Самарского университета. История, педагогика, филология. 2019. Т. 25. № 4. С. 100-105.

4. Мудров А. Н. Основы рекламы: учебник. Изд-е 2-е, пер. и доп. М.: Магистр, 2008. 397 с.

5. Слепович В. С. Настольная книга переводчика с русского языка на английский = Russian-English Translation Handbook. Изд-е 2-е. Мн.: ТетраСистемс, 2006. 304 с.

6. Этно-маркет ZAM [Электронный ресурс]. URL: https://www.zam.market/ (дата обращения: 05.04.2021).

7. Сoca-Cola [Электронный ресурс]. URL: https://web.facebook.com/Coca-Cola/photos/?tab=album\&album_id= 10158694459828306 (дата обращения: 05.04.2021).

8. Danone [Электронный ресурс]. URL: https://www.facebook.com/Danone/posts/2886823594682914 (дата обращения: 05.04.2021).

9. Fennis M. B., Stroebe W. The Psychology of Advertising. Hove, East Sussex - N. Y.: Psychology Press, 2010.331 p.

10. Gucci [Электронный ресурc]. URL: https://www.facebook.com/GUCCI/posts/10158926766541013 (дата обращения: 05.04.2021).

11. Kellogg's Krave US. Krave Cereal [Электронный pecypc]. URL: https://www.facebook.com/watch/?v= 1216350011711524 (дата обращения: 05.04.2021).

12. OVS [Электронный ресурс]. URL: https://www.facebook.com/OVSGlobalPage/posts/3858524494214912 (дата обращения: 05.04.2021).

13. Ray-Ban [Электронный ресурc]. URL: https://www.facebook.com/watch/?v=285578856266319 (дата обращения: 05.04.2021).

\section{Информация об авторах | Author information}

RU Цыремпилон Алина Олеговна ${ }^{1}$, к. филол. н.

Семенова Эржена Васильевна ${ }^{2}$, к. филол. н., доц.

Марактаева Саяна Владимировна ${ }^{3}$

1, 2, 3 Бурятский государственный университет имени Доржи Банзарова, г. Улан-Удэ

EN Tsyrempilon Alina Olegovna ${ }^{1}, \mathrm{PhD}$

Semenova Erzhena Vassilyevna ${ }^{2}, \mathrm{PhD}$

Maraktaeva Sayana Vladimirovna ${ }^{3}$

1,2, 3 Banzarov Buryat State University, Ulan-Ude

${ }^{1}$ tsyr2000@mail.ru, ${ }^{2}$ semenerzh@yandex.ru, ${ }^{3}$ justsayana@gmail.com

\section{Информация о статье | About this article}

Дата поступления рукописи (received): 24.04.2021; опубликовано (published): 30.07.2021.

Ключевые слова (keywords): рекламный дискурс; экспрессивный синтаксис; адекватность перевода; advertising discourse; expressive syntax; adequacy of translation. 